\title{
Analysis of Characteristics of Slurry and Thermal Insulation Materials Using Hauyne Cement
}

\author{
Tae Yeon Kim, Ki Sic Jo, and Yong Sik Chu (1) ${ }^{\dagger}$ \\ Energy and Environmental Division, Korea Institute of Ceramic Engineering and Technology, Jinju 52851, Korea
}

(Received July 3, 2019; Revised September 4, 2019; Accepted September 5, 2019)

\begin{abstract}
This study focused on manufacturing an inorganic insulation material set with various amounts of calcium-sulfoaluminate (CSA) (hauyne) content for enhancing both workability (demolding, handling) and the high thermal insulating property. To carry out the experiment, the amounts of CSA utilized were $5 \%, 10 \%, 15 \%$, and $20 \%$, with anhydrous gypsum added in equal proportion to produce a stable formation. As the content of CSA increased, a sinking phenomenon occurred because of the hydration reaction from the slurry, so it was difficult to utilize a retarder normally used in the cement manufacturing process. However, an RCOOM surfactant was able to solve the local clumping problem from cement and CSA and obtain a rapid retarding effect, so it was included in this process at $0.3 \%$. Furthermore, the cement fineness was not $7000 \mathrm{~cm}^{2} / \mathrm{g}$ but rather $3300 \sim 4000 \mathrm{~cm}^{2} / \mathrm{g}$ to prevent a rapid temperature increase in the slurry. The specific gravity of the sample manufactured with $20 \%$ CSA was approximately $0.11 \mathrm{~g} / \mathrm{cm}^{3}$, and its thermal conductivity was $0.041 \mathrm{~W} / \mathrm{m} \cdot \mathrm{K}$, providing an excellent insulating property.
\end{abstract}

Key words : Inorganic insulation, Cement, Calcium sulfoaluminate, Thermal conductivity, Hardness

\section{Introduction}

$\mathrm{T}$ hermal insulation materials used for buildings can be classified into those made with organic and those made with inorganic materials, and, among those used, more than $70 \%$ are organic insulation materials vulnerable to fire. Consequently, the casualties caused by the fire and toxic gas of organic insulation materials have increased, and studies on inorganic insulation materials have been actively conducted. Furthermore, the development and use of inorganic insulation materials are urgently needed to replace organic insulation materials. ${ }^{1,2)}$ Recently, studies have been conducted on nonflammable insulators using cement as a main material, because they can possess all the advantages of organic and inorganic insulation materials. ${ }^{3-5)}$

For the conventional cement-type inorganic insulation materials, high-Blaine-fineness cement pulverized to approximately $7000 \mathrm{~cm}^{2} / \mathrm{g}$ fineness and high-Blaine-fineness slag pulverized to about $6000 \mathrm{~cm}^{2} / \mathrm{g}$ fineness are used, so that slurry settlement does not occur and the compressive strength characteristic is manifested sufficiently. However, because the setting time of slurry manufactured as described above is very long, the production process is not easy, and consequently the setting time should be shortened by using and mixing calcium-sulfoaluminate (CSA) (hauyne cement,

\footnotetext{
${ }^{\dagger}$ Corresponding author: Yong Sik Chu

E-mail : yschu@kicet.re.kr

Tel : +82-55-792-2463 Fax : +82-55-792-2469

ORCID

https://orcid.org/0000-0002-1023-528X
}

$\mathrm{CaO} \cdot \mathrm{SO}_{3} \cdot \mathrm{Al}_{2} \mathrm{O}_{3}$ ) cement, which is fast setting. However, the CSA mixing ratio is currently only approximately $5 \%$ maximum, which is definitely insufficient to reduce the setting time. This is because, when the CSA mixture ratio exceeds $5 \%$, slurry settlement and poor slurry expansion (large decrease of expansion height and nonuniform expansion) result, and it is impossible to manufacture the slurry. ${ }^{6}$

Therefore, the aim of this study was to derive a method that can fabricate a normal slurry while greatly increasing the CSA mixing ratio (for the prevention of slurry settlement and fabrication of a uniform slurry) to fabricate a hauyne inorganic insulation material. In addition, in this study, an attempt was made to solve a problem that can occur during process production by greatly reducing the setting time of the normally fabricated slurry. ${ }^{7)}$

\section{Experimental Procedure}

Table 1 shows the mix-design ratio changes of CSA content for controlling the setting time of the inorganic insulation material. As shown in Table 1(a), the cement content decreased from $75 \%$ to $45 \%$, and the anhydrite and CSA contents increased from $5 \%$ to $20 \%$. Here, the anhydrite and CSA contents were identically increased by $5 \%$ at a time. Aluminum powder, which is a foaming agent, was fixed at $0.6 \%$, the surfactant at $0.3 \%$, and the mixing water at $130 \%{ }^{8)}$ Table 1(b) shows the mix design ratio that changed the cement and quicklime mixing ratio after fixing the CSA content at $15 \%$, and the quicklime content was increased from $5 \%$ to $20 \%$ in $5 \%$ increments. Here, type- 1 ordinary Portland cement sold in the market was used for the 
Table 1. Mix Design Ratio of Inorganic Insulation Material

(a) Mix design ratio of CSA and cement content changes for fabrication of inorganic insulation material (unit: \%)

\begin{tabular}{ccccccccc}
\hline No. & Cement & Quicklime & Anhydrite & CSA & $\begin{array}{c}\text { Foam } \\
\text { Stabilizer }\end{array}$ & Al Powder & $\begin{array}{c}\text { Surfactant } \\
\text { (RCOOM) }\end{array}$ & $\begin{array}{c}\text { Mixing } \\
\text { Water }\end{array}$ \\
\hline 1 & 75 & 15 & 5 & 5 & 0.05 & 0.6 & 0.3 & 130 \\
2 & 65 & 15 & 10 & 10 & 0.05 & 0.6 & 0.3 & 130 \\
3 & 55 & 15 & 15 & 15 & 0.05 & 0.6 & 0.3 & 130 \\
$3-1$ & 60 & 15 & 15 & 10 & 0.05 & 0.6 & 0.3 & 130 \\
$3-2$ & 50 & 15 & 15 & 20 & 0.05 & 0.6 & 0.3 & 130 \\
4 & 45 & 15 & 20 & 20 & 0.05 & 0.6 & 0.3 & 130 \\
\hline
\end{tabular}

(b) Mix design ratio of cement and quicklime content changes at 15\% CSA condition (unit: \%)

\begin{tabular}{ccccccccc}
\hline No. & Cement & Quicklime & Anhydrite & CSA & $\begin{array}{c}\text { Foam } \\
\text { Stabilizer }\end{array}$ & Al Powder & $\begin{array}{c}\text { Surfactant } \\
\text { (RCOOM) }\end{array}$ & $\begin{array}{c}\text { Mixing } \\
\text { Water }\end{array}$ \\
\hline 5 & 65 & 5 & 15 & 15 & 0.05 & 0.6 & 0.3 & 130 \\
6 & 60 & 10 & 15 & 15 & 0.05 & 0.6 & 0.3 & 130 \\
7 & 55 & 15 & 15 & 15 & 0.05 & 0.6 & 0.3 & 130 \\
8 & 50 & 20 & 15 & 15 & 0.05 & 0.6 & 0.3 & 130 \\
\hline
\end{tabular}

cement, and hauyne cement having an $\mathrm{Al}_{2} \mathrm{O}_{3}$ content of approximately $33 \%$ was used for the CSA. The cement fineness used in this study was at a level of $3300-4000 \mathrm{~cm}^{2} / \mathrm{g}$, not $7000 \mathrm{~cm}^{2} / \mathrm{g}$ used in the conventional method. This is because, when high Blaine fineness cement is used, the internal temperature of the slurry increases rapidly, which increases the foaming speed and, finally, produces slurry settlement. ${ }^{9)}$ The slurry mixed according to Table 1 was poured into a Styrofoam mold $(23 \times 23 \times 23 \mathrm{~cm})$ and cured for $24 \mathrm{~h}$ at $25 \pm 2^{\circ} \mathrm{C}$ (room temperature) and $60 \%$ relative humidity. After $24 \mathrm{~h}$ elapsed, the specimen was demolded and left in air for seven days, thereby testing the thermal conductivity and pore properties. The thermal conductivity was measured by a heat flow meter (HC-076, EKO Company, Japan) specified in KS L 9016 after drying at $100^{\circ} \mathrm{C}$ for $24 \mathrm{~h}$, and the pore properties were examined by using CAMSCOPE (Sometech Vision Company). For the setting time of the slurry placed in the Styrofoam mold, a Vicat needle was used, and the Vicat needle test method was a typical setting-time test method of cement material. ${ }^{6}$

\section{Results and Discussion}

\subsection{Foaming state of slurry}

Figure 1 shows the postfoaming state of the slurry fabricated according to Table 1. As shown in Fig. 1(a), the final foaming height of the slurry did not show much difference from No. 1 to No. 4 (No. $123.0 \mathrm{~cm}$, No. $222.5 \mathrm{~cm}$, No. 322.8 $\mathrm{cm}$, and No. $422.8 \mathrm{~cm}$ ). No. 1 showed the characteristic of expanding to the maximum value and then settling a little, but Nos. 2-4 did not show any settlement phenomenon after completion of foaming. In the settlement phenomenon of No. $1, \mathrm{Ca}(\mathrm{OH})_{2}$ production increased, because the cement content of No. 1 was relatively high. Consequently, a relatively large amount of hydrogen gas contributing to the foam generation was produced (excessive production), and little settlement occurred, as shown in Eq. (1). ${ }^{10)}$ Therefore, when only the slurry foaming state was considered, No. 1 was not suitable for large scale and mass production, but it was determined that Nos. 2-4 could be sufficiently applied to the process.

$$
\begin{aligned}
& 2 \mathrm{Al}+3 \mathrm{Ca}(\mathrm{OH})_{2}+6 \mathrm{H}_{2} \mathrm{O} \rightarrow 3 \mathrm{CaO}+\mathrm{Al}_{2} \mathrm{O}_{3}+6 \mathrm{H}_{2} \mathrm{O}+3 \mathrm{H}_{2} \\
& \text { or } 2 \mathrm{Al}+\mathrm{Ca}(\mathrm{OH})_{2}+6 \mathrm{H}_{2} \mathrm{O} \rightarrow \mathrm{Ca}(\mathrm{Al}(\mathrm{OH}) 4)_{2}+3 \mathrm{H}_{2}
\end{aligned}
$$

Figure 1(b) shows the foaming characteristics according to the cement and quicklime content changes at the 15\% CSA condition. As shown in the figure, the foaming height exhibited a gradually increasing characteristic as the quicklime content increased (the cement content decreased), and the final foaming height was $18.0 \mathrm{~cm}$ for No. $5,20.5 \mathrm{~cm}$ for No. $6,22.8 \mathrm{~cm}$ for No. 7, and $23.5 \mathrm{~cm}$ for No. 8. This was because the $\mathrm{CaO}$ content of quicklime was larger than that in the cement, and this had a larger impact on the hydrogen gas generation, as shown in Eq. (1). Similar to No. 1, No. 8 showed little settlement after foaming, and this study sufficiently confirmed that the excessive hydrogen gas generation contributes to settlement of slurry in the end. Therefore, it was estimated that No. 8, like No. 1, would not be suitable for mass production.

Nos. 3-1 and 3-2 are examples of fabricating slurry by changing the mixing ratio of CSA and anhydrite from conventional $15 \%: 15 \%$ (CSA:anhydrite) to $10 \%: 15 \%$ and $20 \%: 15 \%$. In other words, they are the slurry states that were observed for the cases of not maintaining the same mixing ratio of CSA and anhydrite. Here, Nos. 3-1 and 3.2 slurries showed the settlement phenomenon without maintaining the foaming state in the foaming process or after final foaming, as shown in Fig. 2. Therefore, it is important to maintain the anhydrite content as well as simply increase the CSA content to promote the setting and increase the 


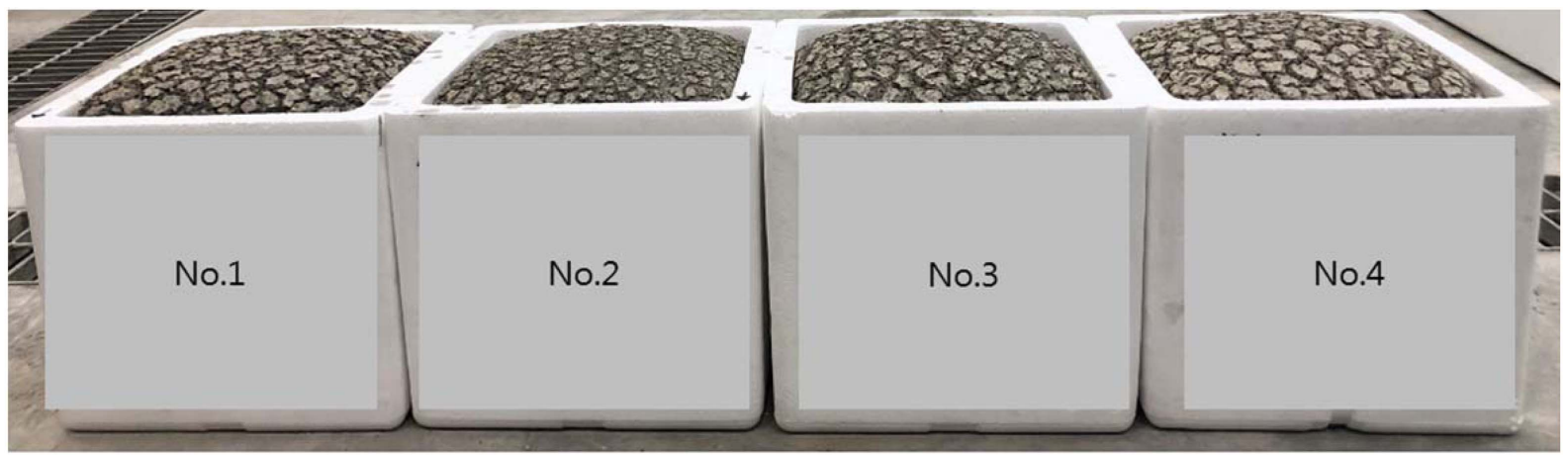

(a) Changes of CSA and cement contents

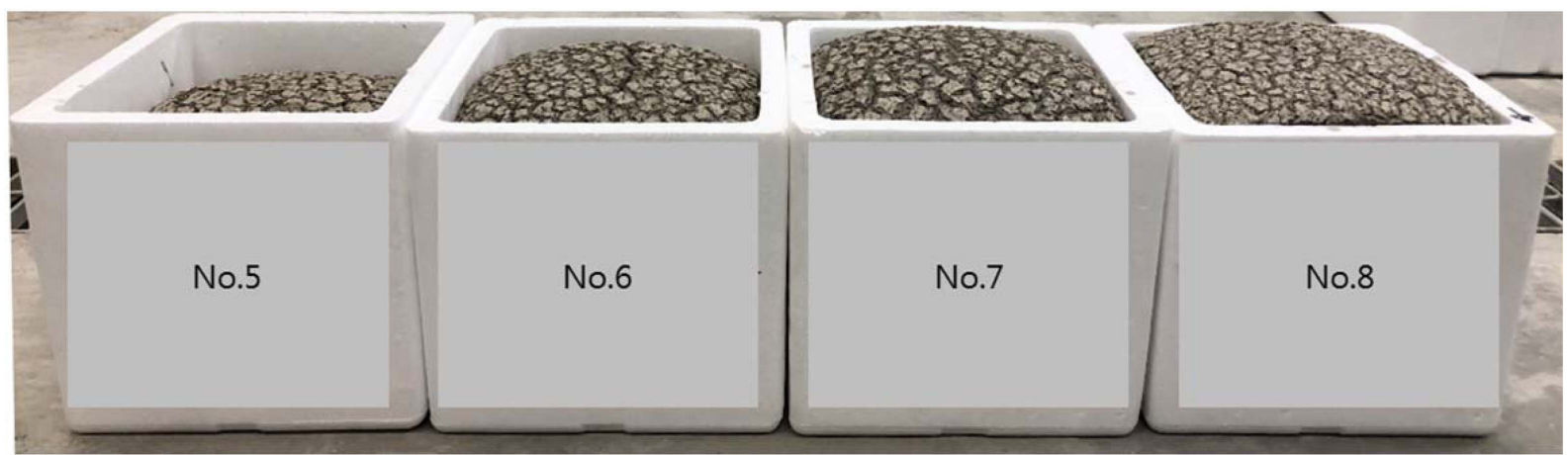

(b) Changes of cement and quicklime at $15 \%$ CSA condition

Fig. 1. Comparison of foaming state of slurry.

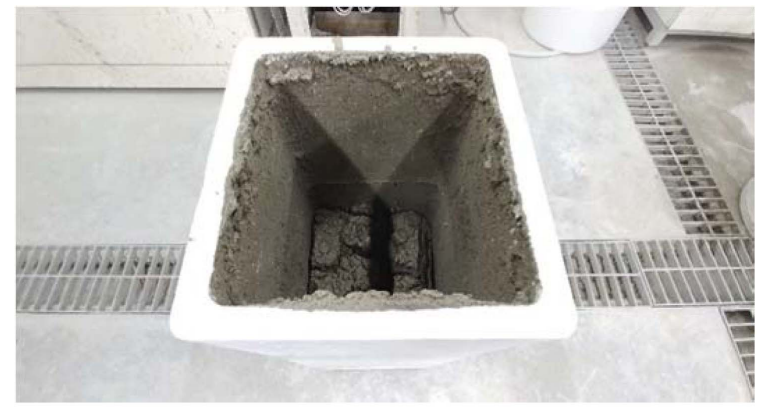

(a) No. 3-1

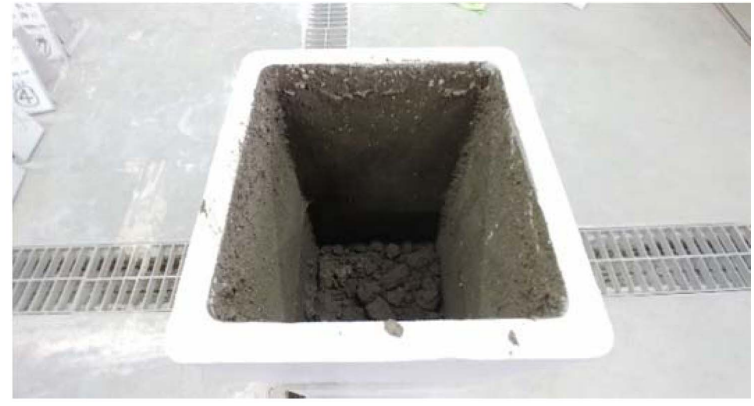

(b) No. 3-2

Fig. 2. Settlement phenomena of Nos. 3-1 and 3-2 slurries.

strength of inorganic insulation material, the final product. ${ }^{11)}$

The quick-setting time control of the slurry is important to prevent the settlement of the slurry using more than 5\% CSA, unlike the calcium silicate insulation material that does not use CSA. In other words, the quick-setting mechanism should be used after foaming, whereby slurry settlement does not occur as quick-setting occurs after completion of slurry foaming (Fig. 3). This means that a quick-setting control factor is added along with the viscosity and temperature, which are considered major factors of the slurry used for conventional thermal insulation materials. Usually, the foaming time of the slurry is approximately $30-40 \mathrm{~min}$.
Therefore, setting should be carried out quickly after 30-40 min, the foaming completion timepoint. However, when the CSA content was $5 \%$ or higher, the quick-setting phenomenon was carried out very quickly in the slurry foaming process, and, consequently, the slurry's nonuniform foaming and settlement phenomena resulted. Therefore, quick-setting control methods that can delay the quick-setting time should be derived, and two methods can be derived. First, as mentioned above, the mixing ratios of CSA and anhydrite are kept identical. This method produces ettringite hydrate through the hydration reaction of CSA and anhydrite and delays the setting based on this. ${ }^{12)}$ Usually, CSA consists of $\mathrm{CaO}, \mathrm{SO}_{3}$, and $\mathrm{Al}_{2} \mathrm{O}_{3}$ and can produce ettringite by itself. ${ }^{13)}$ 


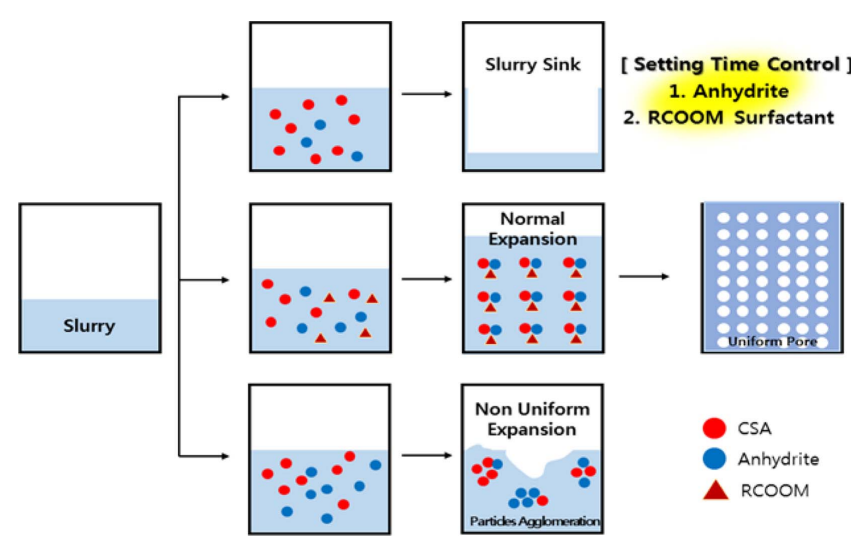

Fig. 3. The concept diagram of normal slurry fabrication factor control at the CSA mixing condition.

However, for fabrication of normal slurry, the ettringite production should be greatly increased by adding more anhydrite compared with the conventional cement mixing level.

Second, the quick-setting problem should be solved according to the local particle agglomeration of cement and CSA inside the slurry. Citric acid and tartaric acid used as usual setting retarders caused many problems when fabricating the CSA slurry. ${ }^{14)}$ In other words, a large number of nonuniform foams occurred inside the slurry, although it is different depending on the citric-acid/tartaric-acid contents, and, in the end, slurry settlement occurred. Therefore, normal slurry could not be fabricated by using the cement-type setting retarder usually used. However, by using the RCOOM surfactant, it was possible to resolve the local agglomeration of CSA and cement and to obtain the quick-setting delay effect. Here, $\mathrm{R}$ refers to $\mathrm{C} 7-17$, and $\mathrm{M}$ refers to potassium, sodium, calcium, and ammonium. When the RCOOM surfactant was used, the quick-setting control effect increased at less than $0.3 \%$, but no more change was observed at more than $0.3 \%$. Therefore, this study conducted the test by fixing at $0.3 \%$.

\subsection{Setting time}

The setting time of the slurry was measured by using a

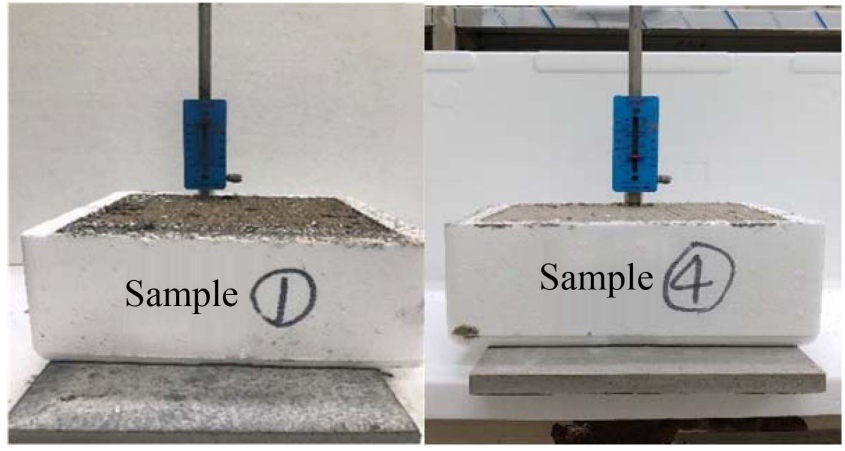

Fig. 4. Examples of setting time measurement using the Vicat needle.

Vicat needle on specimens that had completed foaming, and an example of the measurement is shown in Fig. 4. Fig. 5 shows the result of measuring the Vicat needle penetration depth for $24 \mathrm{~h}$ after the slurry foaming. As shown in Fig. 5, the Vicat needle penetration depth decreased as the time elapsed; particularly, the setting time decreased greatly as the CSA content increased.

Figure 5(a) displays the setting time changes by CSA content, and the Vicat needle did not penetrate after a lapse of $21 \mathrm{~h}$ at $5 \%$ CSA content. However, the Vicat needle did not penetrate after a lapse of $10 \mathrm{~h}$ at $10 \% \mathrm{CSA}$ content, $8 \mathrm{~h}$ at $15 \% \mathrm{CSA}$ content, and $7 \mathrm{~h}$ at $20 \% \mathrm{CSA}$ content. In other words, the time for finishing the setting and transitioning to the hardening state was shortest in the $20 \%$ CSA condition, and this confirmed that the setting time could be reduced by $14 \mathrm{~h}$ compared with 5\% CSA. Furthermore, $13 \mathrm{~h}$ could be reduced for the setting time at $15 \%$ CSA condition. Fig. 5(b) shows the result of measuring the setting time of the slurry by changing the cement and quicklime contents after fixing the CSA content at $15 \%$. No. 5 , which had the lowest quicklime content, showed a slight increase of setting time, but Nos. 6-8 exhibited similar results. Therefore, it was confirmed that the CSA content should be controlled rather than the quicklime content to reduce the setting time.

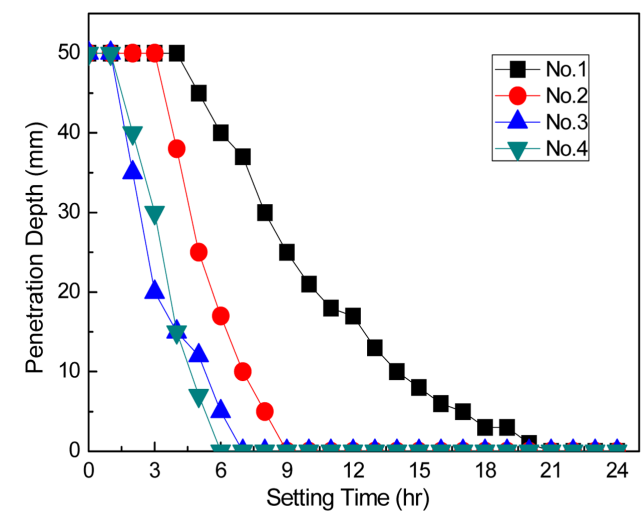

(a) CSA and cement content changes

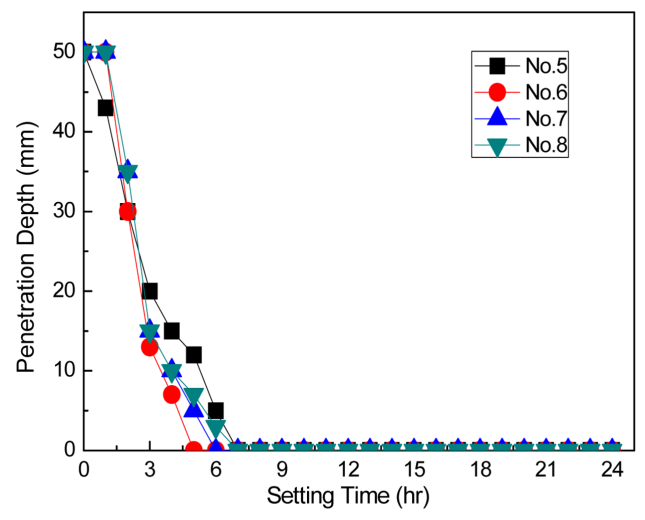

(b) Cement and quicklime content changes

Fig. 5. Setting time characteristics according to the mix design condition. 


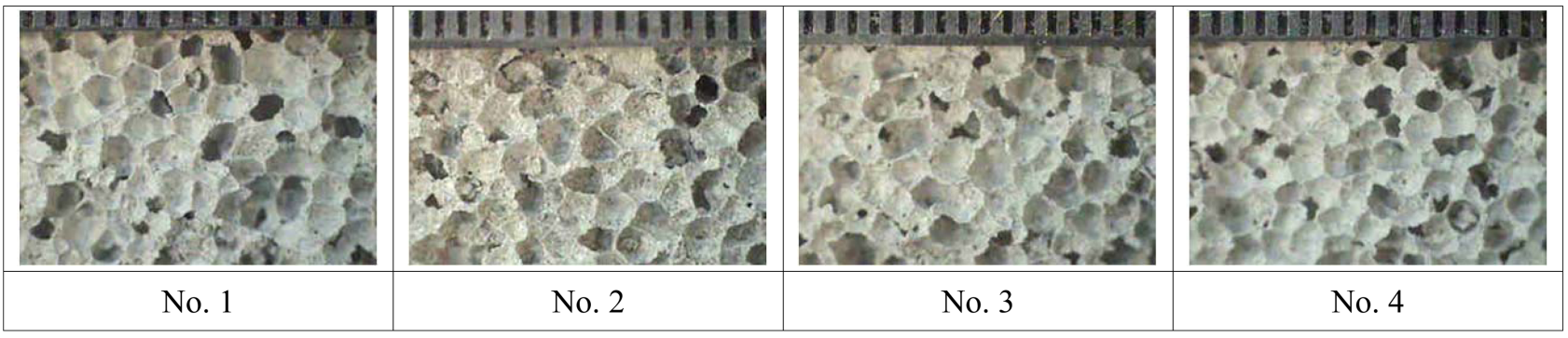

(a) CSA and cement content changes

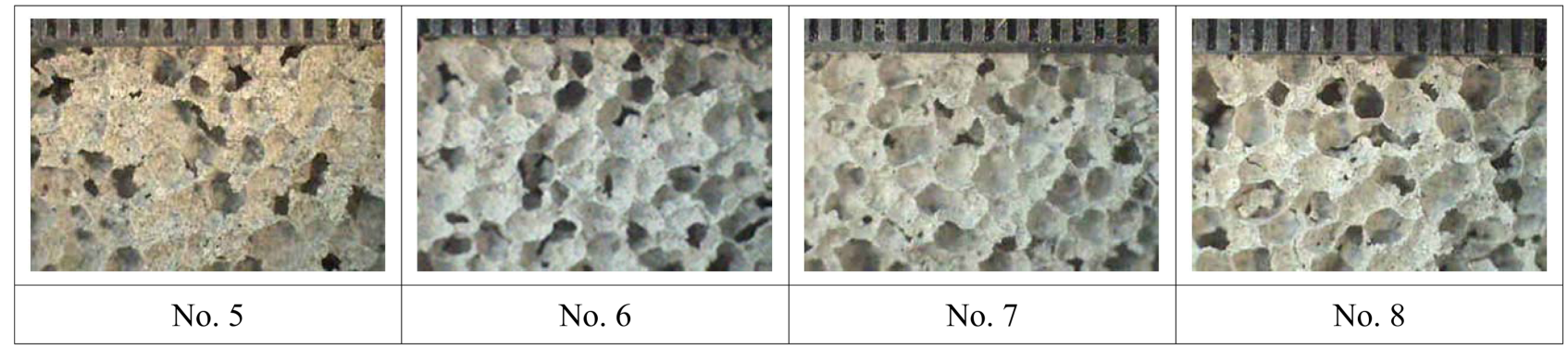

(b) Cement and quicklime content changes

Fig. 6. Pore characteristics of inorganic insulation material by mix design condition.

\subsection{Porosity and thermal insulation characteristics}

After fabricating slurries and leaving them in air for seven days, the porosity and thermal insulation characteristics were analyzed. The pore characteristics of each inorganic insulation material were analyzed by using a camscope, and they are shown in Fig. 6. As shown in Fig. 6, the average pore size of all specimens excluding No. 4 was approximately $2.5 \mathrm{~mm}$.

The pore size of No. 4 was approximately $1-2 \mathrm{~mm}$, and the average pore size was about $1.5 \mathrm{~mm}$, indicating that No. 4 consisted of the smallest pores. Furthermore, it showed a slightly better thermal insulation characteristic than the other specimens.

Figure 7 shows the thermal conductivity characteristic, and all specimens showed similar thermal conduction characteristics. The thermal conductivity was approximately 0.041-0.045 W/mK (No. 1, 0.042W/mK; No. 2, 0.042 W/mK;

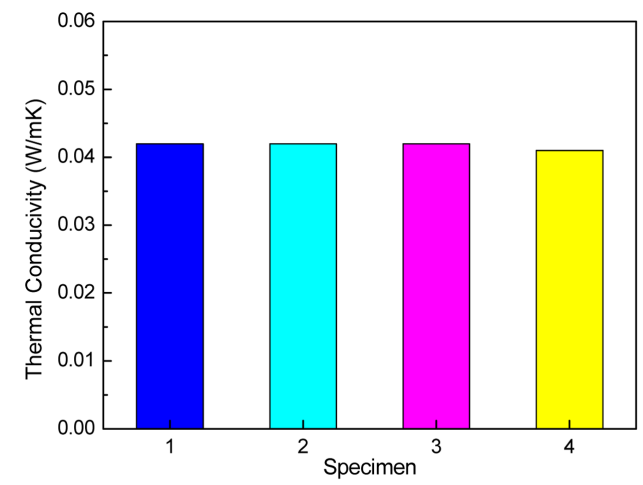

(a) CSA and cement content changes
No. 3, $0.042 \mathrm{~W} / \mathrm{mK}$; No. 4, $0.041 \mathrm{~W} / \mathrm{mK}$; No. 5, $0.045 \mathrm{~W} / \mathrm{mK}$; No. 6, 0.042 W/mK; No. 7, $0.042 \mathrm{~W} / \mathrm{mK}$; No. 8, $0.042 \mathrm{~W} / \mathrm{mK})$. The thermal conductivity of No. 5 was $0.045 \mathrm{~W} / \mathrm{mK}$, showing the highest thermal conductivity. This result was obtained because the amount of foam for heat blocking decreased because of the insufficient quicklime content (5\%). In general, the porosity and thermal conductivity are inversely proportional for lightweight-foamed concrete and cement-type inorganic insulation materials.

\section{Conclusions}

This study aimed to derive methods (slurry settlement prevention and uniform slurry fabrication) that can fabricate normal slurry while increasing the CSA mixing ratio greatly to fabricate inorganic insulation materials using CSA. Furthermore, in this study, an attempt was made to

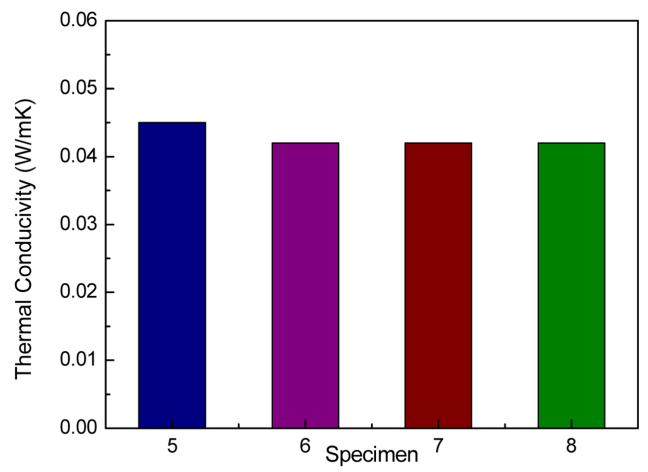

(b) Cement and quicklime content changes

Fig. 7. Thermal insulation characteristic by mix design condition. 
decrease the setting time of the slurry greatly, and, through this, the following conclusions were derived.

(1) The mixing ratio of anhydrite should be similar to the CSA mixing ratio to fabricate the normal slurry by increasing the CSA mixing ratio to $20 \%$. Particularly, when there was more than $5 \%$ difference between the mixing ratio of anhydrite and that of CSA, the slurry settled, and the fabrication of CSA insulation material was impossible.

(2) The type-1 ordinary Portland cement mixed with CSA showed a slurry settlement phenomenon when it was finely powdered, unlike the conventional inorganic insulation material $\left(7000 \mathrm{~cm}^{2} / \mathrm{g}\right)$. Therefore, it was confirmed that the appropriate cement fineness was approximately 3300-4000 $\mathrm{cm}^{2} / \mathrm{g}$, which was not finely powdered.

(2) The particle agglomeration phenomenon and the quick-setting phenomenon should be resolved by using appropriate surfactant when mixing the CSA. Therefore, it was confirmed that the desired effect was obtained using a conventional setting retarder, such as citric acid and tartaric acid, and the RCOOM-type surfactant should be used.

(3) At $15 \%$ and $20 \%$ CSA content, the setting time was reduced by 13 and $14 \mathrm{~h}$, respectively, compared with the $5 \%$ CSA content condition. In other words, when the CSA content increases, the demolding time of CSA inorganic insulation material can be decreased, thereby contributing sufficiently to productivity improvement.

(4) For the majority of CSA insulation materials, the thermal conductivity was approximately $0.041-0.042 \mathrm{~W} / \mathrm{mK}$. The thermal conductivity was $0.045 \mathrm{~W} / \mathrm{mK}$ at $5 \%$ quicklime content condition only. Therefore, more than $5 \%$ should be used for the quicklime content in order to improve the thermal insulation characteristics. This is because, as the quicklime content increases, $\mathrm{Ca}(\mathrm{OH})_{2}$ generation also increases, thereby producing sufficient hydrogen gas. In other words, an appropriate amount of quicklime is required to produce sufficient hydrogen gas for foam generation.

(5) This study demonstrated that thermal insulation materials can be sufficiently fabricated, even at more than $5 \%$ CSA mixing condition, and the fabrication of a CSA insulation material that can decrease the setting time and improve the thermal insulation characteristic is possible.

\section{REFERENCES}

1. J. M. Kim, H. G. Choi, and S. G. Park, "An Experimental Study on the Pore Structure and Thermal Properties of Lightweight Foamed Concrete by Foaming Agent Type," J. Korea Inst. Build. Constr., 9 [4] 63-73 (2009).
2. S. K. Seo, Y. S. Chu, J. K. Lee, H. Song, and J. W. Park, "A Study on Fabrication and Characterization of Inorganic Insulation Material by Hydrothermal Synthesis Method (2)," J. Korean Recycled Constr. Res. Inst., 1 [3] 225-32 (2013).

3. K. H. Lee and C. W. Chae, "A Study on the Amount of the Energy Consumption and $\mathrm{CO}_{2}$ Emission of Public Building using the Input-Output Analysis," Archit. Inst. Korea, 18 [5] 99-107 (2002).

4. S. K. Jeong, J. S. Jeon, and J. K. Seo, "Consideration for Application of Phase Change Material for Building Energy Saving," Korean Inst. Archit. Sustainable Environ. Build. Syst., 5 [1] 1-9 (2011).

5. J. H. Park and T. H. Hoon, "Improvements of Policies Related Building Energy Reduction in Korea," Korea Inst. Constr. Eng. Manage., 11 [4] 14-21 (2010).

6. T. Y. Kim, Y. S. Chu, S. K. Seo, and S. Y. Yoon, "The Property of Inorganic Insulation Material Depending on CSA Contents and Atmospheric Steam Curing Condition," J. Ceram. Process. Res., 19 [5] 407-12 (2018).

7. J. T. Song, J. S. Jeo, and J. Y. Jeon, "Preparation and Properties of CSA Type Expensive Cement Using Industrial By-products,” J. Korean Ceram. Soc., 38 [2] 183-92 (2001).

8. S. K. Seo, Y. S. Chu, J. K. Lee, H. Song, and J. W. Park, "A Study on Fabrication and Characterization of Inorganic Insulation Material by Hydrothermal Synthesis Method (1)," J. Korean Recycled Constr. Res. Inst., 1 [3] 219-24 (2013).

9. L. Zhang and F. P. Glasser, "Hydration of Calcium Sulfo Aluminate Cement at Less Than 24 h," Adv. Cem. Res., 14 [4] 141-55 (2002).

10. J. Y. Park, J. H. Jeong, and Y. S. Chu, "Physical Properties of Calcium Silicate Inorganic Insulation Depending on Curing Time," J. Korea Inst. Build. Constr., 16 [6] 52934 (2016).

11. Y. G. Jeo, C. S. Kim, S. Y. Nam, S. H. Jeo, H. W. Lee, and J. H. Ahn, "Characterization of Foamed Concrete Using Calcium Sulfoaluminate," The Korean Society of Energy, 28 [1] 10-6 (2019).

12. K. N. Hong, J. Y. Jeong, and S. H. Han, "Material Properties of Grout Using Alumina Cement and Anhydrite," $J$. KOSOS, 26 [5] 59-64 (2011).

13. C. G. Han, M. H. Lee, J. M. Park, and Chang Chun Pei, "Early Quality Improvement of Concrete Incorporating CSA Admixture," Archit. Inst. Korea, 22 [4] 127-34 (2006).

14. C. H. Chang, W. S. Lee, Y. W. Jung, and Y. I. Chung, "Strength Properties of Concrete According to Types of High Early Strength Cement and Curing Method," $J$. Korean Recycled Constr. Res. Inst., 5 [1] 76-84 (2017). 